\title{
The neuroprotective effect of Sulindac after ischemia-reperfusion injury in rats ${ }^{1}$
}

\author{
Murat Cosar', Tuncay Kaner", Onder Sahin" ${ }^{\mathrm{III}}$, Naci Topaloglu' ${ }^{\mathrm{IV}}$, Mustafa Guvenv, Adem Bozkurt Aras ${ }^{\mathrm{VI}}$, Tarık Akman ${ }^{\mathrm{VI}}$, Adile \\ Ozkan $^{\text {VII }}$, Halil Murat Sen ${ }^{\text {VII }}$, Gulsum Memi ${ }^{\text {III }}$, Mustafa Deniz ${ }^{\text {IX }}$ \\ DOI: http://dx.doi.org/10.1590/S0102-86502014000400008 \\ ${ }^{\mathrm{I}} \mathrm{PhD}$, Full Professor, Department of Neurosurgery, Canakkale 18 March University (COMU), Canakkale, Turkey. Acquisition and interpretation of \\ data, scientific and intellectual content of the study. \\ IIAssociate Professor, Department of Neurosurgery, Medeniyet University, Istanbul, Turkey. Conception and design of the study, critical revision.

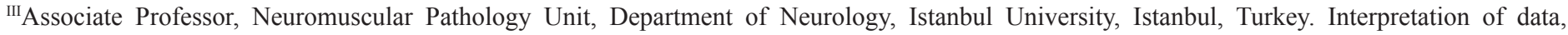 \\ manuscript writing, critical revision.

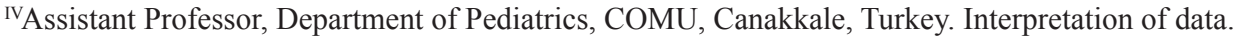 \\ ${ }^{\mathrm{v}}$ Assistant Professor, Department of Neurosurgery, COMU, Canakkale, Turkey. Interpretation of data, critical revision. \\ ${ }^{\mathrm{VI}}$ Assistant Professor, Department of Neurosurgery, COMU, Canakkale, Turkey. Interpretation of data. \\ ${ }^{\mathrm{VII}}$ Assistant Professor, Department of Neurology, COMU, Canakkale, Turkey. Interpretation of data. \\ ${ }^{\mathrm{VIII}} \mathrm{PhD}$ degree, Department of Physiology, Health School, Trakya University, Kırklareli, Turkey. Histopathological examinations, interpretation of data. \\ ${ }^{\mathrm{Ix}}$ Associate Professor, Department of Physiology, COMU, Canakkale,Turkey. Histopathological examinations, interpretation of data.
}

\section{ABSTRACT}

PURPOSE: To investigate the neuroprotective effects of Sulindac on the hippocampal complex after global cerebral ischemia/reperfusion $(\mathrm{I} / \mathrm{R})$ injury in rats.

METHODS: Thirty one Sprague-Dawley rats were used, distributed into group I (sham) n:7 were used as control. For group II (n:8), III (n:8) and IV (n:8) rats, cerebral ischemia was performed via the occlusion of bilateral internal carotid artery for 45 minutes and continued with reperfusion process. $0.3 \mathrm{~mL} / \mathrm{kg} / \mathrm{h} 0.9 \%$ sodium chloride was infused intraperitoneally to the Group II rats before ischemia, $5 \mu \mathrm{g} / \mathrm{kg} / \mathrm{h} / 0.3$ $\mathrm{ml}$ sulindac was infused intraperitoneally to the Group III rats before ischemia and $5 \mu \mathrm{g} / \mathrm{kg} / \mathrm{h} / 0.3 \mathrm{ml}$ sulindac was infused intraperitoneally to the Group IV rats after ischemia and before reperfusion process. The levels of MDA, GSH and MPO activity were measured in the left hippocampus tissue. The hippocampal tissue of all group members were taken for histopathological study.

RESULTS: The MDA and MPO levels increased from group I (control) to group II $(\mathrm{I} / \mathrm{R})(\mathrm{P}<0.05)$ and decreased from group II (I/R) to group III (presulindac + I/R) and IV (postsulindac + I/R) $(\mathrm{P}<0.05)$. Beside these, the GSH levels decreased from group I (control) to group II $(\mathrm{I} / \mathrm{R})(\mathrm{P}<0.05)$ and increased from group II $(\mathrm{I} / \mathrm{R})$ to group III (presulindac $+\mathrm{I} / \mathrm{R})$ and IV (postsulindac $+\mathrm{I} / \mathrm{R})(\mathrm{P}<0.05)$.

The number of apoptotic neurons increased from group I (control) to group II (I/R) $(\mathrm{P}<0.05)$ and decreased from group II (I/R) to group III (presulindac + I/R) and IV (postsulindac $+\mathrm{I} / \mathrm{R})(\mathrm{P}<0.05)$.

CONCLUSION: The Sulindac may have neuroprotective effects on ischemic neural tissue to prevent the reperfusion injury after ischemia. Key words: Reperfusion Injury. Neuroprotective Agents. Sulindac. Rats, Sprague-Dawley. 


\section{Introduction}

Patients exposed to acute stroke have an area of severely affected brain tissue, the ischemic core, which is irreversibly damaged. Previous studies demonstrated that apoptosis plays a crucial role in progression of injury because of brain ischemia ${ }^{1}$. After the primary neuronal cell injury, secondary neuronal damage via inflammation occurs following reperfusion of the ischemic tissue, which also plays a role in the progress of brain damage, called as reperfusion injury. So, the aim of many clinicians is to prevent neural ischemia-reperfusion injury.

The pathophysiology of ischemia-reperfusion injury includes the release of reactive oxygen species (ROS), accumulation and infiltration of neutrophils, inflammatory cytokines, macrophages and activation of proteases ${ }^{2}$. The excessive production of ROS in ischemia-reperfusion causes to a considerable oxidative stress as indicated by lipid peroxidation ${ }^{3}$. Superoxide anions, hydroxyl free radicals and hydrogen peroxide called as ROS are produced as a consequence of metabolic reactions during central nervous system activity ${ }^{4}$. ROS are directly involved in oxidative stress and damage of cellular macromolecules such as nucleic acids of proteins and lipids in ischemic tissues, which may lead to apoptosis and cell death ${ }^{5}$. Inflammatory mediators based from the leukocytes can produce hypotension, metabolic acidosis, and tissue damage which may lead to organ dysfunction ${ }^{6}$.

Sulindac is a non-selective aldose reductase inhibitor ${ }^{7}$. It has also antipyretic, analgesic, anticarcinogenic and anti-inflammatory properties. Beside the its primary mechanism such as inhibition of prostaglandine synthesis by inhibiting cyclo-oxygenase constitutes, also the free radical scavenging activity of it for all ROS and reactive nitrogen species may strongly contribute to its anti-inflammatory activity $^{7}$. In addition to all these, a growing body of evidence shows that Sulindac has remarkable neuroprotective effects via reduction of protein oxidation in neuroischemic diseases ${ }^{8,9}$.

Although the free radical scavenging activity, the inhibitory and anti-inflammatory activities of sulindac on aldose reductase have known, the neuroprotective effect of sulindac against ischemia-reperfusion injury has not been evaluated, yet. The aim of the present study is to investigate the protective effect of sulindac, a non-selective aldose reductase inhibitor, against to ischemia-reperfusion injury in rats.

\section{Methods}

Experiments were performed in accordance with the "Animal Welfare Act and the Guide for the Care and Use of
Laboratory animals prepared by the Marmara University, Animal Ethical Committee". Thirty one Sprague-Dawley rats (aged 8-12 weeks) weighing $280 \pm 20$ g (mean \pm SD) obtained from the Laboratory Animal Production Unit of Marmara University was used in the study. They were kept in a controlled temperature, humidity, and controlled photoperiod environment for one week before the start of the experiment. A commercial balanced diet and tap water were provided $\mathrm{ad}$ libitum. All animals received humane care in compliance with institutional guidelines.

\section{Experimental design}

Thirty one rats divided into 4 groups (each animal was placed separately in a stainless-steel cage). Group I rats (sham, $\mathrm{n}=7$ ) were used as control. Group II ( $/ \mathrm{R}+0.9 \% \mathrm{NaCl}, \mathrm{n}=8)$, group III $(\mathrm{I} / \mathrm{R}+$ pre-sulindac, $\mathrm{n}=8)$ and group IV $(\mathrm{I} / \mathrm{R}+$ post-sulindac, $\mathrm{n}=8$ ) rats were the rest groups. The animals of all groups were anaesthetized with ketamine $(100 \mathrm{mg} / \mathrm{kg}$; ip) and chlorpromazine (12.5 mg/kg, ip)

For group I rats, the neck incision was left open for $45 \mathrm{~min}$, but the common carotid arteries (CCA) and vertebral arteries were not occluded. This group of animals was used to determine the effects of anesthesia and operation over the results.

For group II, III and IV rats, they were prepared for I/R model via occlusion of bilateral CCA. For this purpose, bilateral CCA were exposed with a transverse ventral neck incision and bilateral CCA were occluded with aneurysm clips for 45 minutes, followed by 6 hours of reperfusion.

For group II, the rats received $0.3 / \mathrm{kg} / \mathrm{h} 0.9 \% \mathrm{NaCl}$ intraperitoneally before I/R injury. For group III, the rats received $5 \mu \mathrm{g} / \mathrm{kg} / \mathrm{h} / 0.3 \mathrm{ml}$ sulindac intraperitoneally before ischemia process (45 minutes) and the situation followed with 6 hours reperfusion. For group IV, the rats received $5 \mu \mathrm{g} / \mathrm{kg} / \mathrm{h} / 0.3 \mathrm{ml}$ intraperitoneally after 45 minutes ischemia process and the situation followed with 6 hours reperfusion.

Rats of all groups were sacrificed via decapitation. Craniotomy was also performed in groups I, II, III and IV. The brains were removed immediately after sacrification of animals. The left hippocampal formations of all animals were dissected and washed with ice cold isotonic $\mathrm{NaCl}$ to remove residual blood. Tissues were stored at $-70{ }^{\circ} \mathrm{C}$ until biochemical analysis. The right hemispheres were blocked for histopathological analysis. 


\section{Biochemical analyses}

The frozen tissue samples of hippocampal tissue were weighed and homogenized (Ultra Turrax T25, Germany) (1:10, $\mathrm{w} / \mathrm{v})$ in $50 \mathrm{mmol} \mathrm{L}^{-1}$ phosphate buffer ( $\left.\mathrm{pH} 7.4\right)$ kept in an ice bath. The protein content of the tissue samples was determined using the Lowry method ${ }^{10}$.

\section{Tissue myeloperoxidase measurements}

Tissue-associated myeloperoxidase (MPO) activity was determined in 0.2- to 0.3 -g samples. Tissue samples were homogenized in 10 vols of ice-cold potassium phosphate buffer (20 $\mathrm{mM}$ K2HPO, $\mathrm{pH}$ 7.4). The homogenate was centrifuged at 12,000 rpm for $10 \mathrm{~min}$ at $4^{\circ} \mathrm{C}$. MPO activity was assessed by measuring the $\mathrm{H}_{2} \mathrm{O}_{2}$-deependent oxidation of o-dianisidine $\cdot 2 \mathrm{HCI}$. One unit of enxyme activity is defined as amount of the MPO present that causes a change in absorbance of $1.0 \mathrm{~min}^{-1}$ at $460 \mathrm{~nm}$ and $37^{\circ} \mathrm{C}^{6}$.

\section{Tissue malondialdehyde (MDA) and glutathione (GSH) measurement}

Tissue samples were homogenized in 10 volumes of ice-cold $10 \%$ trichloracetic acid and centrifuged at $3000 \mathrm{rpm}$ for $15 \mathrm{~min}$ at $4^{\circ} \mathrm{C}$. The supernatant was transferred to a test tube containing an equal volume of TBA $(0.67 \% \mathrm{w} / \mathrm{v})$, and this mixture was then heated to $90^{\circ} \mathrm{C}$ and maintained at that temperature for 15 minutes. The MDA concentration for each specimen was determined in a spectrophotometer based on level of absorbance at $532 \mathrm{~nm}$, and was expressed as nmol/g tissue ${ }^{11}$. GSH measurements were performed using a modification of the Ellman procedure ${ }^{12}$. GSH levels were calculated using an extinction coefficient of $1 \cdot 36 \times 10^{5} \mathrm{M} / \mathrm{cm}$. Results are expressed in $\mu \mathrm{mol} \mathrm{GSH} / \mathrm{g}$ tissue.

\section{Histological examination}

Comparisons of levels of neuronal cell death were made from the number of morphologically intact cells and the number of black-stained picnotic cells for the evaluation of apoptosis and necrosis. Sections were stained with haematoxyline and eosin (H\&E), which shows black-stained picnotic cells in the hippocampal CA1, CA2, CA3, and dentate gyrus (DG) regions and Cresyl violet acetate, which shows selective staining of Nissl granules (tigroid bodies and Nissl bodies) in the hippocampal CA2 regions. The numbers of cells in each group were counted separately in four hippocampal areas (two areas each per portion) of the hippocampal regions per section. Mounted slides were examined under a light microscope (Nikon Microscope ECLIPSE E600W, Tokyo, Japan) and photographed using a digital camera (Microscope Digitale Camera DP20, Tokyo, Japan). The images were processed by an IBM-compatible personal computer, highresolution video monitor and image analysis software (BS200 Docu Version 2.0, BAB Imaging Systems, Ankara, Turkey) camera and optical microscope. The method requires preliminary software procedures of spatial calibration (micron scale) and setting of color segmentation for quantitative color analysis ${ }^{13}$. The number of apoptotic cells was calculated as an average per rat.

\section{Statistical analysis}

Data is presented as means \pm standard deviation (SD). A computer program (SPSS 15.0, Chicago, IL, USA) was used for statistical analysis. Distribution of the groups was analyzed with a Shapiro-Wilks test. They were analyzed using a Kruskal-Wallis H-test. Differences between two groups were determined with a Mann-Whitney U-test. $\mathrm{P}<0.05$ was considered statistically significant.

\section{Results}

\section{Biochemical analysis}

\section{MDA levels}

As shown in Figure 1, MDA levels were 15.3 \pm 1.179 $\mathrm{nmol} / \mathrm{g}$ protein (mean $\pm \mathrm{SD}$ ) in group I (control), 26.72 \pm 4.86 $\mathrm{nmol} / \mathrm{g}$ protein in group II (I/R), $14.09 \pm 1.21 \mathrm{nmol} / \mathrm{g}$ protein in group III (I/R + pre-sulindac) and $15.97 \pm 1.13 \mathrm{nmol} / \mathrm{g}$ protein in group IV (I/R + post-sulindac).

According to these values, MDA levels were significantly higher in group II than in group I $(\mathrm{P} \leq 0.05)$. Additionally, the MDA levels were significantly lower in group III and IV than in group II $(\mathrm{P} \leq 0.05)$.

\section{MPO activity}

As seen in Figure 1, MPO activities were $3.22 \pm 0.71$ $\mathrm{nmol} / \mathrm{g}$ tissue (mean $\pm \mathrm{SD}$ ) in group I (control), $11.8 \pm 1.67 \mathrm{nmol} / \mathrm{g}$ tissue in group II (I/R), $5.51 \pm 0.86 \mathrm{nmol} / \mathrm{g}$ tissue in group III $(\mathrm{I} / \mathrm{R}+$ pre-sulindac) and $5.091 \pm 1.37 \mathrm{nmol} / \mathrm{g}$ tissue in group IV (I/R + post-sulindac). According to these values, MPO activity were significantly higher in group II than in group I $(\mathrm{P} \leq 0.05)$. Additionally, the MPO activity were significantly lower in group III and IV than in group II $(\mathrm{P} \leq 0.05)$. 

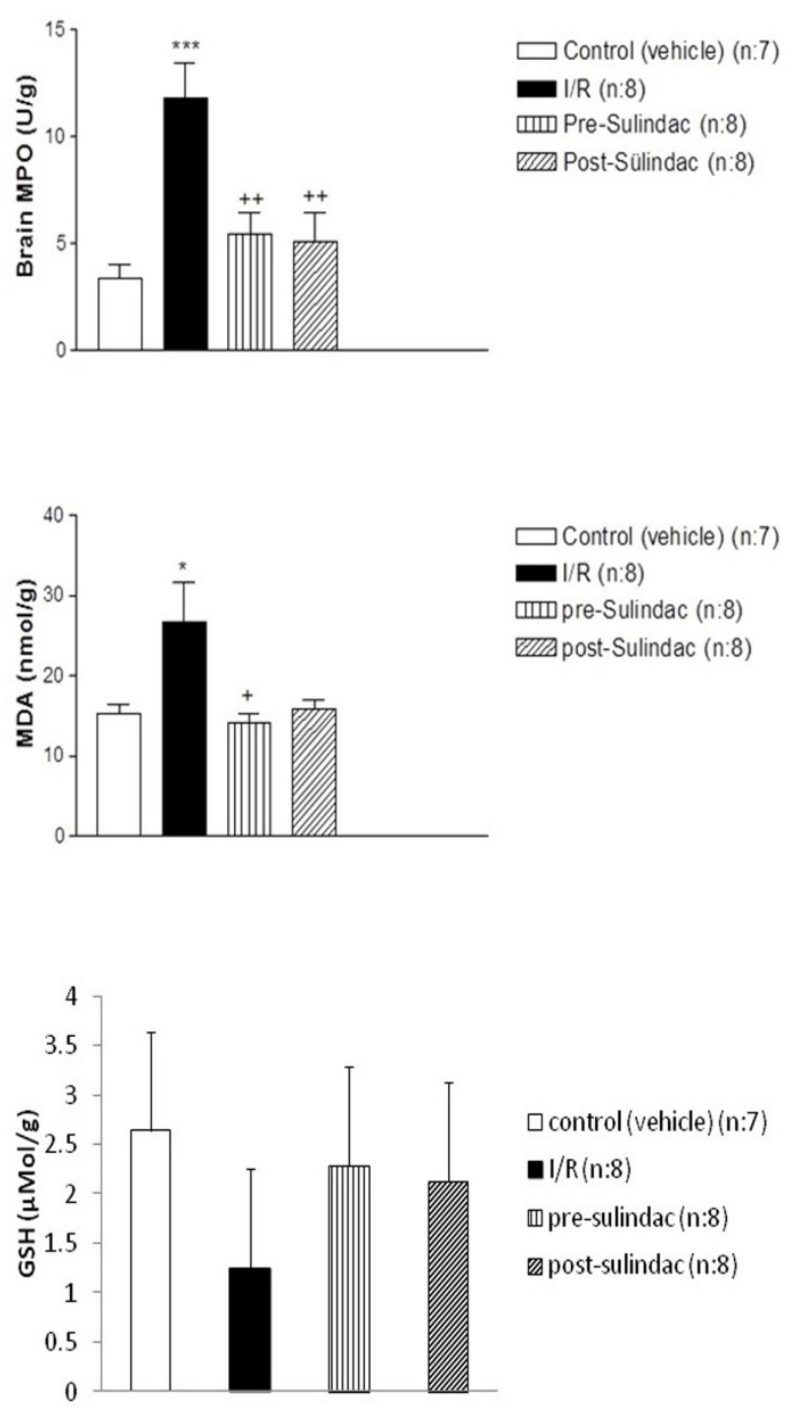

FIGURE 1 - Hippocampal tissue MDA, MPO and GSH levels.

\section{$\underline{\text { GSH levels }}$}

As seen in Figure 1, GSH levels were $2.64 \pm 0.27 \mu \mathrm{mol}$ $\mathrm{GSH} / \mathrm{g}$ tissue in group I (control), $1.25 \pm 0.15 \mu \mathrm{mol} \mathrm{GSH} / \mathrm{g}$ tissue in group II (I/R), $2.28 \pm 0.17 \mu \mathrm{mol} \mathrm{GSH} / \mathrm{g}$ tissue in group III (I/R + pre-sulindac) and $2.12 \pm 0.17 \mu \mathrm{mol} \mathrm{GSH} / \mathrm{g}$ tissue in group IV (I/R + post-sulindac). According to these values, GSH levels were significantly lower in group II than in group I $(\mathrm{P} \leq 0.05)$. Additionally, the GSH levels were significantly higher in group III and IV than in group II $(\mathrm{P} \leq 0.05)$.

\section{Apoptotic cells}

The results of the apoptotic neuron quantification in the hippocampus proper and dentate gyrus are shown in Figure 2.

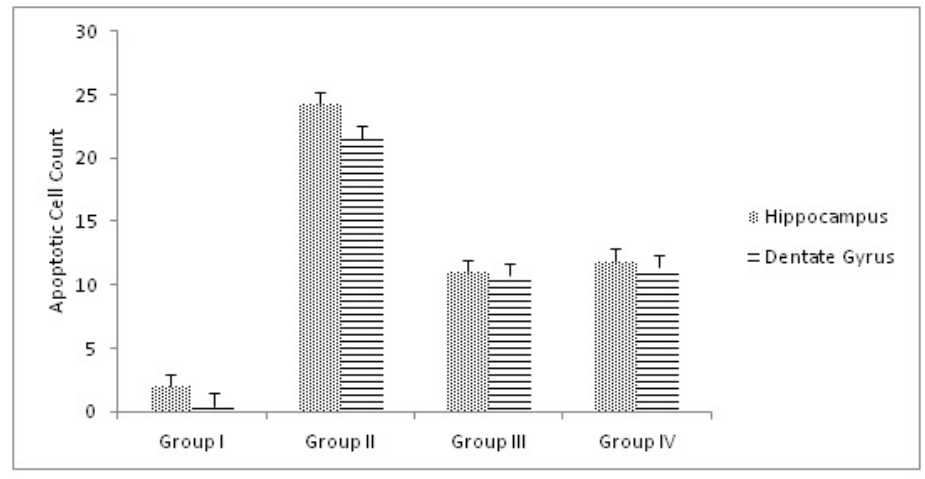

FIGURE 2 - Apoptotic cell quantification in hyppocampus and dentate gyrus.

These results showed that the number of apoptotic neurons was significantly higher in group II than in group I $(p=0.003)$. Additionally, the number of apoptotic neurons was significantly lower in group III than in group II $(\mathrm{p}=0.002)$. Figures 3 and 4 show the H\&E and Cresyl violet acetate stained sections of the hippocampal tissue.

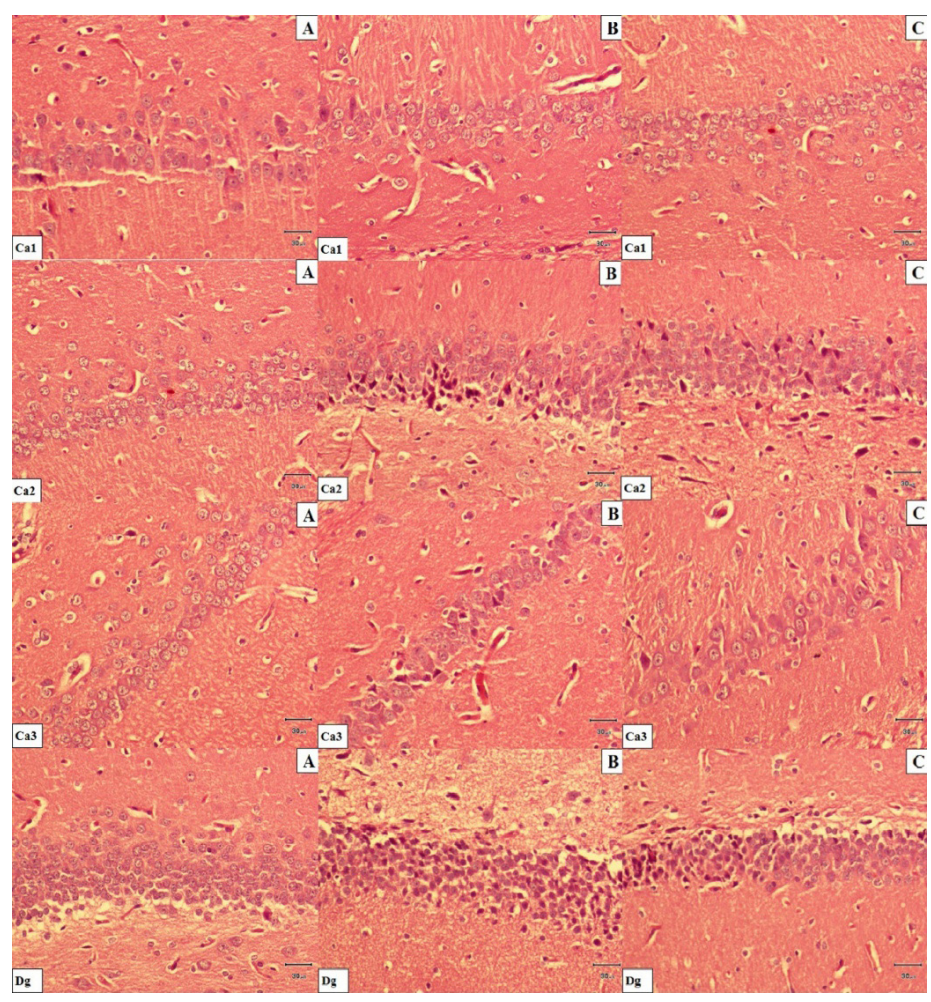

FIGURE 3 - In a H\&E, stained sections. A. Hippocampal tissue histology in control rats. B. Hippocampal tissue histology Group II rats (I/R) group rats. Severe degenerative changes and shrinkage cytoplasma and extensively dark picnotic nuclei are seen in neuronal cells. C. Less degenerative changes and slight shrunken in cytoplasma and nuclei are seen in neuronal cells. Hippocampal tissue histology in group III (I/R + pre-sulindac, ) and group IV (I/R + post-sulindac, ) rats. Scale bar $=30 \mu \mathrm{m}$. 


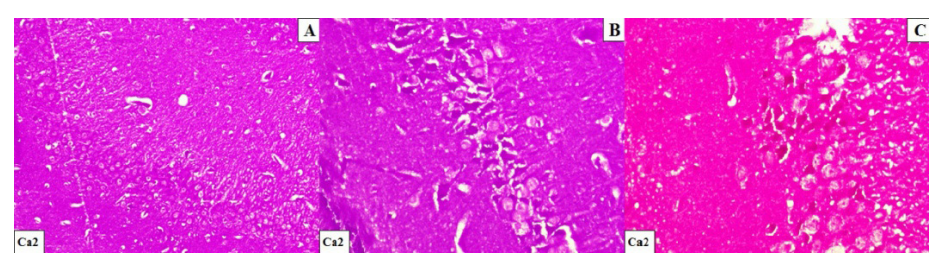

FIGURE 4 - In a Cresyl violet acetate stained sections, CA2 region. A. Hippocampal tissue histology in control rats. B. Hippocampal tissue histology Group II rats group rats. Extensively increase dark picnotic nuclei and selective staining of Nissl granules (tigroid bodies and Niss bodies) in the hippocampal. C. Hippocampal tissue histology in group III (I/R + pre-sulindac, ) group IV (I/R + post-sulindac, ) and rats. Decrease Nissl granules (tigroid bodies and Nissl bodies) Cresyl violet acetate $\mathrm{x} 200$

\section{Discussion}

The hippocampus located in the middle of the brain, has many functions such as learning, memory, analysis of knowledge, cognition, and communication. As it has been demonstrated in the literature, the neural structures especially the hippocampal area has a specific vulnerability to ischemia-reperfusion injury process $^{8,14,15}$.

In this study, we examined the effects of sulindac on cerebral global I/R injury in the rats' hippocampal formation. I/R injury in the absence of sulindac administration produced increase in MDA levels, MPO activity and number of apoptotic neurons of hippocampal tissue. In contrast, sulindac administration together with $\mathrm{I} / \mathrm{R}$ showed decrease in the production of MDA levels, MPO activity and number of apoptotic neurons in hippocampal tissue. Where as, GSH levels of hippocampal tissue did not show statistical difference between the control, I/R and sulindac administrated groups. So, we hypothesized that Sulindac may have neuroprotective effect via decreasing the oxidative stress after I/R injury in the hippocampal tissue of rats.

Oxygenation following reperfusion in the I/R process is responsible for the influx of free oxygen radicals and secondary tissue damage ${ }^{16}$. Free oxygen radicals play major role in tissue injury developing after ischemia-reperfusion ${ }^{17}$. PMN leukocytes (neutrophil etc.) and endothelial cells are the main source of free oxygen radicals beside the inflammation process. Microglia, macrophages and granulocytes are the inflammatory cells which cause to inflammatory response of the brain to injury, also, participating in the expansion of ischemic damage following reperfusion ${ }^{18}$. These inflammatory cells produce some pro-inflammatory mediators such as adhesion molecules, cytokines and chemokines.

The oxidative stress, which develops after ischemiareperfusion, causes imbalance between the ROS and antioxidants. This beginning of the process is accused for the progression of neural injury like its similar effects in various tissues ${ }^{18}$. Numerous studies revealed that ROS are directly involved in oxidative damage of cellular macromolecules such as proteins, lipids, and nucleic acids in tissues $5,7,17,19$. Neural structures especially hippocampus are the most vulnerable organs which are affected by ischemic-reperfusion injury ${ }^{8,14}$. In our study, we used MDA, MPO and GSH to demonstrate the level of I/R injury and the possible protective effect of Sulindac on the oxidative stress.

MDA, which is both an indicator and effector of oxidative stress, occurs from the breakdown of lipid peroxyl radicals and also oxidizes protein molecules. The consensus on the literature about the ischemia-reperfusion injury revealed that the prevention of ischemic-reperfusion injury, especially for neural structures, depends on a complex cycle of free oxygen radical formation, neutrophil sequestration, lysosomal enzyme and complement activation and endothelial cell damage ${ }^{6}$. These processes also causes to the augmented levels of lipid peroxidation (LPO) products in cellular membranes ${ }^{11}$. MDA is a commonly used parameter for the determination of LPO and oxidative damage which forms as a product of $\mathrm{LPO}^{4}$. In our study, MDA levels were significantly lower in sulindac administered I/R rats (group III and IV) compared to $I / R$ rats. This showed that $I / R$ rats had more LPO in the hippocampus, which caused oxidative damage. The administration of Sulindac (group III and IV) decreased MDA levels compared to group II. So, Sulindac may have a positive effect on the structure of membrane phospholipids in $\mathrm{I} / \mathrm{R}$ rats, which decreases the levels of MDA in group III and IV.

It is well known that ischemic process causes to activation and recruitment of neutrophils at the effected neural tissue. Several studies showed the role of neutrophil at the I/R injury. MPO activity, which is an essential enzyme for normal neutrophil function is released as a response to various stimulations ${ }^{6}$. In our study, we evaluated the I/R injury via the contribution of neutrophil infiltration and also the level MPO activity. The study showed that MPO activity were significantly lower in sulindac administered $\mathrm{I} / \mathrm{R}$ rats (group III and IV) compared to I/R rats (group II). So that, the administration of sulindac (group III and IV) decreased MDA levels compared to I/R group II. This results showed that the presence of elevated MPO activity in the brain indicates that $\mathrm{I} / \mathrm{R}$-induced injury involves the contribution of neutrophil infiltration. Moreover, increased MPO activity due to I/R injury was effectively reversed by Sulindac administiration.

The increase of oxidative damage after hippocampal ischemia occurs via the oxidation of proteins, lipids and DNA by peroxynitrite $^{15}$. In agreement with our observation, the GSH levels decrease with cerebral I/R injury ${ }^{20}$. In addition to these, decreased GSH level due to I/R injury (group II) was effectively reversed by 
Sulindac administiration (group III and IV).

In the present study, we have also observed the genetically programmed cell death known as apoptosis in all pathological specimens of right hippocampal tissues of 4 groups. However, the number of apoptotic neurons was different in all groups.

When we looked at the pathological data of the study, we observed that Sulindac was reducing the incidence of apoptosis in the I/R neural tissue. In other words, the number of apoptotic cells in the Sulindac groups (III and IV) was significantly lower than the number of apoptotic cells in the I/R group (I) $(\mathrm{P}<0.05)$ (Figure 1).

\section{Conclusion}

Sulindac ameliorates the oxidative stress and apoptotic changes in rat hippocampal neural tissue following cerebral ischemia/reperfusion injury.

\section{References}

1. Charriaut-Marlangue C, Margaill I, Represa A, Popovici T, Plotkine $\mathrm{M}$, Ben-Ari Y. Apoptosis and necrosis after reversible focal ischemia: an in situ DNA fragmentation analysis. J Cereb Blood Flow Metab. 1996;16:186-94.

2. Zhao ZQ, Vinten-Johansen J. Myocardial apoptosis and ischemic preconditioning. Cardiovasc Res. 2002;55:438-55.

3. Fleckenstein AE, Smith SL, Linseman KL, Beuving LJ, Hall ED. Comparison of the efficacy of mechanistically different antioxidants in the rat hemorrhagic shock model. Circ Shock. 1991;35:223-30.

4. Lancelot E, Callebert J, Revaud ML, Boulu RG, Plotkine M. Detection of hydroxyl radicals in rat striatum during transient focal cerebral ischemia: possible implication in tissue damage. Neurosci Lett. 1995; 197:85-8.

5. Chan PH. Reactive oxygen radicals in signaling and damage in the ischemic brain. J Cereb Blood Flow Metab. 2001;21:2-14.

6. Winterbourn CC, Kettle AJ. Reactions of myeloperoxidase with superoxide and hydrogen peroxide: significance for its function in the neutrophil. Basic Life Sci. 1988;49:823-7.

7. Fernandes E, Toste SA, Lima JL, Reis S. The metabolism of sulindac enhances its scavenging activity against reactive oxygen and nitrogen species. Free Radic Biol Med. 2003;35:1008-17.

8. Dairam A, Muller AC, Daya S. Non-steroidal anti-inflammatory agents, tolmetin and sulindac attenuate quinolinic acid (QA)-induced oxidative stress in primary hippocampal neurons and reduce QAinduced spatial reference memory deficits in male Wistar rats. Life Sci. 2007;80:1431-8.

9. Xing Y, Zhang X, Zhao K, Cui L, Wang L, Dong L, Li Y, Liu Z, Wang C, Zhang X, Zhu C, Qiao H, Ji Y, Cao X. Beneficial effects of sulindac in focal cerebral ischemia: a positive role in Wnt/betacatenin pathway. Brain Res. 2012;1482:71-80.

10. Lowry $\mathrm{OH}$, Rosebrough NJ, Farr AL, Randall RJ. Protein measurement with the Folin phenol reagent. J Biol Chem. 1951;193:265-75.

11. Buege JA, Aust SD. Microsomal lipid peroxidation. Methods Enzymol. 1978;52:302-10.

12. Beutler E, Gelbart T. Improved assay of the enzymes of glutathione synthesis: gamma-glutamylcysteine synthetase and glutathione synthetase. Clin Chim Acta. 1986;158:115-23.
13. Kumral A, Ozer E, Yilmaz O, Akhisaroglu M, Gokmen N, Duman N, Ulukus C, Genc S, Ozkan H. Neuroprotective effect of erythropoietin on hypoxic-ischemic brain injury in neonatal rats. Biol Neonate. 2003;83:224-8.

14. Eser O, Fidan H, Sahin O, Cosar M, Yaman M, Mollaoglu H, Songur A, Buyukbas S. The influence of dexmedetomidine on ischemic rat hippocampus. Brain Res. 2008;1218:250-6.

15. Urabe T, Yamasaki Y, Hattori N, Yoshikawa M, Uchida K, Mizuno Y. Accumulation of 4-hydroxynonenal-modified proteins in hippocampal CA1 pyramidal neurons precedes delayed neuronal damage in the gerbil brain. Neuroscience. 2000;100:241-50.

16. Rotstein OD. Modeling the two-hit hypothesis for evaluating strategies to prevent organ injury after shock/resuscitation. J Trauma. 2003;54:S203-6.

17. McCord JM. Oxygen-derived free radicals in postischemic tissue injury. N Engl J Med. 1985;312:159-63.

18. Glantzounis GK, Tselepis AD, Tambaki AP, Trikalinos TA, Manataki AD, Galaris DA, Tsimoyiannis EC, Kappas AM. Laparoscopic surgery-induced changes in oxidative stress markers in human plasma. Surg Endosc. 2001;15:1315-9.

19. Oktem F, Ozguner F, Mollaoglu H, Koyu A, Uz E. Oxidative damage in the kidney induced by $900-\mathrm{MHz}-e m i t t e d$ mobile phone: protection by melatonin. Arch Med Res. 2005;36:350-5.

20. Mukherjee PK, Ahamed KF, Kumar V, Mukherjee K, Houghton PJ. Protective effect of biflavones from Araucaria bidwillii Hook in rat cerebral ischemia/reperfusion induced oxidative stress. Behav Brain Res. 2007;178:221-8.

\section{Correspondence:}

Onder Sahin

Istanbul University, Department of Neurology

Neuromuscular Pathology Unit

Istanbul, Turkey

Phone: +90 505345461

Fax: +902124142000

ondersahin34@gmail.com

Received: Dez 12, 2013

Review: Feb 14, 2014

Accepted: March 11, 2014

Conflict of interest: none

Financial source: none

${ }^{1}$ Research performed at Laboratory Animal Unit, Marmara University, Istanbul, Turkey. 